\title{
THE RELATIONSHIP BETWEEN PHYSICAL ENDURANCE AND PHYSICALACTIVITY LEVEL OF A COMMUNITY IN KUALA LUMPUR, MALAYSIA.
}

\author{
Journal website at; \\ http://mrtbjournal.org/index.php/njmr/issue/current/showToc \\ AYIESAH, R., S. NUR SURAYA \\ Physiotherapy Programme, \\ Faculty of Allied Health Sciences, Universiti Kebangsaan Malaysia. \\ Jalan Raja Muda Abdul Aziz, 50300, \\ Kuala Lumpur. \\ Correspondence to: \\ Ayiesah Ramli Telephone: \\ 603-26878003 \\ kamalia086@gmail.com.
}

\section{SUMMARY}

Background: Regular exercise and physical activity are important to the physical and mental health of an individual and this can improve balance and the increase endurance to handle the physical and emotional challenges. A society with healthy lifestyle promotes longevity besides enjoying the health benefits of regular exercise.

Objective: This study was undertaken to determine the relationship between physical endurance and physical activity level of a community in Kuala Lumpur.

Methods: Inclusion criteria included subjects aged 45 to 84 years old and is ambulant without support whilst exclusion criteriae are subjects who cannot follow command and is dependent on walking aids or with disability. This cross sectional study uses International Physical Activity Questionnaire (IPAQ) to determine the physical activity level and the 6 Minute Walk Test (6MWT) to determine the physical endurance level. There were $33.3 \%(n=15)$ male and $66.7 \%(n=30)$ female with mean age of 61.24 years old.

Results: Findings demonstrated that $26(48 \%)$ subjects reported having moderate physical activity level whilst 19 (42\%) reported high physical activity level. In 6MWT, several factors affected the 6 minute walked distance (6MWD) to include age ( $r=-0.449)$, height $(r=0.795)$, leg length $(r=0.880)$, leg fatigue ( $r=-0.147)$ and gender. Men who are taller obtained farther 6MWD when compared to women and older person. Among all these factors, only age, height and leg length have significant relationship to $6 \mathrm{MWD}$ with $\mathrm{p}<0.05$. Leg length was observed to influence the step length $(\mathrm{r}=0.827)$, stride length $(\mathrm{r}=0.830)$ and walking speed $(\mathrm{r}=0.806)$. Age was also found to influence leg fatigue $(\mathrm{r}=0.394, \mathrm{p}=0.005)$ and walking speed, $(\mathrm{r}=-$ $0.491, \mathrm{p}=0.005$ ) respectivley.

Conclusion: Older subjects were reported to have a higher leg fatigue and slower walking speed when compared younger subjects. As age increases, the amount of physical activity and physical endurance reduces. However, the physical endurance of the individual was found not to be influence by their physical activity level as measured by the 6 MWT and IPAQ.

KEY WORDS: 6 Minute Walk Test, physical activity level, physical endurance, IPAQ, community

\section{INTRODUCTION}

Physical activity are body movement made by the skeletal muscle which produces energy (Schutzer and Graves, 2004) and is measured in kilocalorie unit. There are many types of physical activities involving activities of daily life like sweeping the floor, washing the car and carrying sport activities like swimming and bicycling. There is close relationship between physical activities and physical endurance. Physical activity is the basis to achieving a good physical endurance level. Therefore, if an individual did not do any physical activities then their physical endurance level will be low and vise versa (Caspersen et al., 1985). Physical endurance level of an individual can also be determined by looking into the 
physical activities of the individuals. An individual is considered to have a good physical endurance level if they can carry out moderate to high intensity of physical activities (Pate et al., 1995). According to American College of Medicne (2002), physical endurance is the ability to carry out high intensity of physical activities without feeling of fatigue. Another definition of physical endurance includes a set of attributes which is owned or achieved by an individual in relation to his or her ability to do physical activity (Pate et al., 1995).

Many studies previously have measured physical activity level using International Physical Activity Questionnaire (IPAQ) (Kahn et al., 2002 ) and physical endurance level can be carried out using the 6-Minutes Walk Test (6 MWT) (Enright et al., 2003) .There are many advantages to an individual health status when one are physically active. There is improved cardiovascular and respiratory function (Kannel and Sorlie, 1979) when one is physically active and, all the muscles inside the body especially the heart and the respiratory muscles have to work harder to meet the body metabolic demand which will be increasing. If physical activities are continuosly and frequently done, then the cardiovascular endurance and stamina of an individual can be improved which later can reduce the risk of getting coronary artery disease (Kannel and Sorlie, 1979).

Knowledge of the amount of physical activity performed in different populations worldwide is however limited. Many developing countries especially lack data on physical activity level (Brown et al., 2004). Thus, it is the objecive of this study to determine the physical activity level among the community in Kuala Lumpur and whether the physical endurance of these individuals is influence by their physical activity level.

\section{METHODOLOGY}

This is a cross-sectional study carried out at Kampung Baru, Kuala Lumpur. Ethical approval was obtained from the Ethical Committee Board in National University of Malaysia. Inclusion criteria include subjects age 45 to 84 years old and is ambulant without support. Exclusion criteria include subjects who cannot follow command and is dependent on walking aids or with disability. Posters informing of the study was placed on the noticed board at the community center in Kampung Baru and Bangunan Yayasan Selangor. The subjects were initially interviewed and those interested were evaluated and given the questionnaires to filled up.

\section{Instrumentation used}

International Physical Activities Questionnaire (IPAQ) The International Physical Activities Questionnaire (IPAQ)(Kahn et al., 2002 ) was used to determine the physical activities among subjects in their daily life. The questionnaire consist of seven parts determining the amount of day and duration spend by the subject to be physically active for the past one week. Findings from these questionnaire will be further classify into three levels that is high, moderate and low according to the categorization of IPAQ, indicating the subjects physical activity level.

\section{6-Minutes Walk Test (6MWT)}

The 6-Minutes Walk Test was used to determine the physical endurance level of the subjects by the distanced walked. They are required to walk for six minutes along the pathway provided 30 meters in length. This test was easy to carry out and is cost effective (Wu et al., 2008 ). Subjects was asked to walk on a flat and hard surface for 30 meters. At the end of the pathway, subjects were required to make a turn around the cone and walk back on the same pathway for six minutes duration. During this test, subjects was ask about their leg fatigue prior to the test carried out at the second minute, fourth minute and at end of the test. Subjects was given the Visual Analogue Scale (VAS) to reflect their leg fatigue. The VAS has a score from 0 to 10 with 0 meaning no fatigue and 10 representing extreme fatigue.

Consent form and International Physical Activity Questionnaire were given to the subjects prior to carrrying out the 6-Minutes Walk Test. The subject had to repeat the 6MWT for three times with 30 minutes rest in between each test. The farthest distance covered between the three test were recorded.

\section{RESULTS}

There are 45 subjects aged 45 to 84 years old who participated in this study consisting of $33.3 \%(n=15)$ male and $66.7 \%(n=30)$ female with mean age $61.24 \pm 10.23$ years old. For male subjects the mean age was $62.80 \pm$ 10.79 years old whilst among the female subjects is 60.47 \pm 10.04 years old. In ethnic groups, there are $88.9 \%(n=40)$ Malay and $11.1 \%(\mathrm{n}=5)$ Chinese.

\section{Relationship of IPAQ and 6MWT}

According to the IPAQ categorization findings demonstrates $42.2 \%(n=19)$ subjects have high physical activity level and $57.8 \%(\mathrm{n}=26)$ reported moderate physical activity level.In 6MWT, differences in the scores of 6MWT was observed in each test. There was an increase in the distance covered between the three tests with the mean distance for test one, two and three are $472.82( \pm 67.64) \mathrm{m}$, $530.30( \pm 65.40) \mathrm{m}$ and $552.33( \pm 56.63) \mathrm{m}$ respectively.Evaluation of pre and post heart rate, respiratory rate and leg fatigue carried out during the 6MWT demonstrated marked increase in the leg fatigue as the subjects finish the test ( Table 1). The mean score for leg fatigue for the second, fourth and sixth minute are $1.89( \pm 0.49), 3.09( \pm 0.55)$ and $4.16( \pm 0.87)$ respectively. The mean step length, stride length and walking speed for overall subjects were $0.70( \pm 0.07) \mathrm{m}, 1.41( \pm 0.14) \mathrm{m}$ and $1.53( \pm 0.16) \mathrm{ms}-1$ respectively ( Table 2$)$. 
Table 1: Level of Physical Activities Among Subjects

\begin{tabular}{|c|c|c|c|c|c|}
\hline & \multicolumn{2}{|c|}{$\begin{array}{l}\text { Days doing the } \\
\text { physical activities }\end{array}$} & \multicolumn{3}{|c|}{$\begin{array}{ll}\text { Duration doing } \\
\text { physical activities }\end{array}$} \\
\hline & $\begin{array}{l}1 \\
\mathbf{n}(\%)\end{array}$ & $\begin{array}{l}2 \\
\mathbf{n}(\%)\end{array}$ & $\begin{array}{l}3 \\
\mathbf{n}(\%)\end{array}$ & $\begin{array}{l}4 \\
\mathrm{n}(\%)\end{array}$ & $\begin{array}{l}5 \\
\mathrm{n}(\%)\end{array}$ \\
\hline \multicolumn{6}{|c|}{$\begin{array}{l}\text { Amount of days and } \\
\text { duration spend for heavy }\end{array}$} \\
\hline physical activity & $11(24)$ & $33(74)$ & 1(2) & $33(73)$ & $12(27)$ \\
\hline \multicolumn{6}{|c|}{$\begin{array}{l}\text { Amount of days and } \\
\text { duration spend for moderate }\end{array}$} \\
\hline physical activity & $0(0)$ & $34(76)$ & $11(24)$ & $19(42)$ & $25(58)$ \\
\hline
\end{tabular}

Amount of days and

duration spend for low

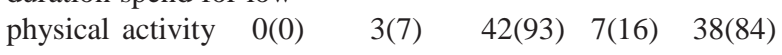

$1=$ None, $2=1-3$ days, $3=>3$ days, $4=<40$ minutes, $5=>40$ minutes

Table 2: Difference in heart rate, respiratory rate and leg fatigue before and after $6 \mathrm{MWT}$

\begin{tabular}{lll}
\hline & Before & After \\
\hline Heart Rate & $76.16 \pm 5.49$ & $107.16 \pm 8.16$ \\
Respiratory Rate & $15.62 \pm 2.19$ & $32.05 \pm 2.50$ \\
L & $0.00 \pm 0.00$ & $4.16 \pm 0.87$
\end{tabular}

There were differences in the distanced walked between male and female subjects with males walking farther than 35.14 meters than females, though no significant difference $(\mathrm{p}=0.236)$ was observed, A moderately significant inverse relationship was observed between age and 6MWD ( $\mathrm{r}=-0.449, \mathrm{p}=0.002)$. This indicates that as age increases, the 6 MWD covered by the subjects was reduced. Findings demonstrates strong correlation between height and 6MWD $(r=0.795, p=0.05)$ with taller subjects, walking farther 6MWD. Leg length and 6MWD, also demonstrates strong significant relationship $(\mathrm{r}=0.880, \mathrm{p}=0.005)$. However, a weak inverse relationship was found between leg fatigue and 6MWD $(r=-0.147, p=0.337)$ with leg fatigue observed despite the shorter distanced walked.

\section{Step Length, Stride Length and Walking Speed.}

There was a very strong significant relationship ( $\mathrm{r}=0.827, \mathrm{p}=0.001$ ) between leg length and step length $(\mathrm{r}=0.830, \mathrm{p}=0.001)$ as well as for leg length and stride length ( $\mathrm{r}=0.806$ and $\mathrm{p}=0.001$ ). There was also a moderate direct relationship between age and leg fatigue $(\mathrm{r}=0.394, \mathrm{p}=0.002)$. The relationship between age and walking speed demonstrated that there was moderate inverse relationship ( $r=-0.491, p=0.001)$. As age increases, the walking speed was reduced. For gender, a significant difference $(p=0.025)$ in walking speed was found with male walking faster than female with walking speed of $1.60( \pm 0.16) \mathrm{ms}-1$ and female at $1.50( \pm 0.15) \mathrm{ms}-1$ as observed in Table 3 .
Table 3: The Average Step Length, Stride Length And Walking Speed Among Subjects

\begin{tabular}{llll}
\hline & Overall & Male & Female \\
\hline Step length (m) & $0.70 \pm 0.07$ & $0.73 \pm 0.05$ & $0.69 \pm 0.08$ \\
Stride length (m) & $1.41 \pm 0.14$ & $1.47 \pm 0.11$ & $1.38 \pm 0.15$ \\
Walking speed (ms-1) & $1.53 \pm 0.16$ & $1.60 \pm 0.16$ & $1.50 \pm 0.15$ \\
\hline
\end{tabular}

\section{Physical Activity}

There was a weak inverse relationship between physical activity level and age $(r=0.231, p=0.127)$. As age increases, the lower is their physical activity level. Relationship between physical activity level and gender demonstrated no significant difference in physical activity level between male and female $(\mathrm{p}=0.670)$. There was no correlation between physical activity level and 6MWD $(\mathrm{p}=0.435)$.

\section{Different Intensity of Physical Activities and 6MWD}

Among the heavy physical activity level, the subjects who spend four days a week doing heavy physical activities have the highest mean for 6MWD $(618.00 \pm 0.00) \mathrm{m}$. In the moderate physical activity these subjects spends 5 days a week and their best mean distanced walked was $601.50( \pm 54.48) \mathrm{m}$ as observed in Table 4. Among subjects who spend 5 days a week walking was observed to have the highest mean distanced walked of $581.36 \mathrm{~m}( \pm 40.39)$. The intensity of physical activity demonstrates that subjects who spend more than 40 minutes to do their physical activities have the highest mean distanced walked for 6MWT when compared to subjects who spend less than 40 minutes (Table 5).

Table 4: Mean 6MWD For Different Intensities of Physical Activities Based On Days Spend In One week

\begin{tabular}{llll}
\hline & \multicolumn{3}{c}{$\begin{array}{l}\text { 6MWD } \\
\text { (Mean } \pm \text { SD) }\end{array}$} \\
& $\begin{array}{l}\text { Heavy Physical } \\
\text { Activity (meter) }\end{array}$ & $\begin{array}{l}\text { Moderate Physical } \\
\text { Activity (meter) }\end{array}$ & $\begin{array}{l}\text { Walking } \\
\text { (meter) }\end{array}$ \\
\hline None & $507.55 \pm 49.78$ & - & - \\
1 Day & $563.64 \pm 46.38$ & $480.00 \pm 0.00$ & - \\
2 Days & $575.18 \pm 62.90$ & $518.20 \pm 45.66$ & $501.00 \pm 29.70$ \\
3 Days & $557.00 \pm 46.37$ & $553.82 \pm 52.67$ & $445.00 \pm 0.00$ \\
4 Days & $618.00 \pm 0.00$ & $563.78 \pm 68.70$ & $526.29 \pm 58.42$ \\
5 Days - & $601.50 \pm 54.45$ & $581.36 \pm 40.39$ \\
6 Days - & - & $557.70 \pm 32.11$ \\
7 Days - & - & $553.71 \pm 69.63$ \\
\hline
\end{tabular}

Table 5 : Mean 6MWD For Different Physical Activities Intensity Based on Minutes Spend in One Session

6MWD ( Mean \pm SD )

Heavy Physical Moderate Physical Walking

Activity (meter) Activity (meter) (meter)

\begin{tabular}{lll}
\hline Less than 40 & & \\
minutes $547.61 \pm 53.59$ & $543.05 \pm 53.29$ & $531.29 \pm 35.16$ \\
$\begin{array}{l}40 \text { minutes and } \\
\text { more } \quad 565.33 \pm 64.97\end{array}$ & $559.12 \pm 59.05$ & $556.21 \pm 59.28$ \\
\hline
\end{tabular}




\section{DISCUSSION}

The male subjects could walk farther than the female subjects because of the their physical appearance as the male subjects are taller than the female subjects. They have a longer step length resulting in the farther 6 minute walked distance similar to findings of Enright et al. (2003). Relationships between 6MWD and age demonstrates that there was an inverse relationship between age and 6MWD demonstrating that as one increases in age, the 6MWD was reduced. The shorter 6MWD was reported among subjects who are older due to the changes in their skeletal muscles (Chetta et al., 2009) with reduction in strength and skeletal muscles density that occur parallel with increasing age resulting in shorter distanced walked among older subjects.

Height and leg length are directly related to 6MWD. The taller the individual the longer is the step length and is one contibuting factors to better 6MWD covered by taller subjects (Poh et al., 2006 ). There was a weak inverse relationship between leg fatigue and 6MWD ( $\mathrm{r}=-0.147$, $\mathrm{p}=0.337$ ). Leg fatigue was reported at the end of 6MWT despite a shorter distance walked in six minutes (Solway et al., 2001).

Leg length had a very strong direct relationship with step length ( $\mathrm{r}=0.827)$, stride length $(\mathrm{r}=0.830)$ and walking speed $(r=0.806)$ with $p<0.005$. If the subject has longer leg length, than they have longer step length, stride length and faster walking speed. Age has a large influence on leg fatigue and walking speed. There was a moderately direct relationship between leg fatigue and age $(r=0.394, p=0.002)$ as older subjects have a higher leg fatigue than the younger subjects (Carter et al., 2003).

In relation to age and walking speed, there was a moderate inverse correlation $\quad(r=0.491, p=0.001)$ demonstrating older subjects have slower walking speed due to changes in musculoskeletal characteristics (Chetta et al., 2009) and this findings is incongruent with studies done by Hageman and Blanke (1986) and Judge et al. (1996). There was significant difference in walking speed between male and female subjects with the average speed in male at $1.60 \pm 0.16 \mathrm{~ms}-1$ and $1.50 \pm 0.15 \mathrm{~ms}-1$ for female similar to findings of Samson et al.(2001). These difference in physical characteristics between male and female are due to males being taller than female and able to walk faster and gained a longer 6MWD (Camarri et al., 2005).

About $42.2 \%(n=19)$ subject reported high physical activity level and $57.8 \%(\mathrm{n}=26)$ subjects reported moderate physical activity level. No subject reported low physical activity level. There was a strong inverse relationship between physical activities level and age. Findings demonstrated that as the subject's age increases the amount of physical activity done was reduced indicating low physical activity level similar to study done by Sherar et al. (2006) . There was no significant difference in the physical activity level between male and female subjects which contravenes findings of Sherar et al. (2006) where physical activity level was measured using an accelerometer compared to this study that measured physcial actvity level using IPAQ questionnaire. No significant relationship between physical activity level and 6MWD was observed demonstrating that an individual with shorter 6MWD does not necessarily have low physical activity level compared to subjects that reported high physical activity level to have a longer 6MWD (Pitta et al., 2005). This is not consistent to findings of Pitta et al. (2005) that demonstrated the more active the individual, the farther is the 6MWD.

Individual that spend 4 days in a week in heavy physical activity was observed to have the longest 6MWD $(618 \pm 0.00)$ compared to those who spends 5 days a week doing moderate physical activity $(601.50 \pm 54.45)$. Among the three levels of physical activity, only those with moderate physical activity shows an ascending pattern where the more days an individual spend to do physical activity, the farther the distance walked achieved by that individual subjects consistent with study of Mader et al. (2004). The duration an individual spend doing the physical activity in each session demonstrated that if they spend more than 40 minutes in one session, than the 6MWD was farther than those individual who spend less than 40 minutes for all three categories.

\section{CONCLUSION}

There are many factors that influence the 6MWD like gender, age, height, leg length and leg fatigue. The younger males, and taller subject have farther walked distanced compared to the female, elderly that is shorter. Leg length also influence the step length, stride length and walking speed. Subjects with longer step length have longer stride length and walked faster. Leg fatigue and walking speed was seen to to have an effect on age. The older the subjects, a higher leg fatigue and reduce in walking speed. Age was observed to have a big effect in the physical activity carried out by the individuals. As the subject's age increases, the amount of physical activity reduces though no significant relationship between physical activity level and 6MWD were observed. Therefore, the 6MWD cannot be an indicator to the physical activity level and vise versa because a person who is reported to have a high physical activity level does not necessarily presents with an increased 6MWD.

\section{ACKNOWLEDGEMENT}

We would want to thank the head of the Physiotherapy Department and staff for supporting this project.

\section{REFERENCES}

- American Collge Of Sports Medicne, (2002) American College of Sports Medicine applauds recognition of physical activity in new Institute of Medicine dietarty guidelines, but warns of confuscion and misunderstanding about IOM specifics Indianapolis, IN;. press release, September 18, 2002.

- Brown, W. J., Bauman, A. \& Chey, T. E. A. (2004) 
Comparison of surveys used to measure physical activity. . Aust N Z J Public Health. 28: 128-34.

- Camarri, B., Easrmood, P. R., Cecins, N. M., Thompson, P. J. \& Jenkins, S. (2005) Six minutes walk distance in healthy subjects ages 55-75 years. Respiratory Medicine, 100: 658665.

- Carter, R., Holiday, D. B., Stocks, J., Grothues, C. \& Tiep, B. (2003) Predicting oxygen uptake for men and women with moderate to severe chronic obstructive pulmonary disease. Archive of Physical Medicine and Rehabilitation. 84: 1158-1164.

- Caspersen, C. J., Powell, K. E. \& Christenson, G. M. (1985) Physical activity, exercise and physical fitness : definition and distinction for health-related research..Public Health Reports. 100: 126-131.

- Chetta, A., Zanini, A., Pisi, G., Aiello, M., Tzani, P., Neri, M. \& Olivieri, D. (2006) Reference value for the 6-Minute Walk Test in healthy subjects 20-50 years old Resp Med., 100: $1573-1578$.

- Enright, P. L., Mcburnie, M. A. \& Bittner, V. (2003) The 6min walk test. A quick measure of functional status in elderly adults. Chest. 123: 387-398.

- Hageman, P. A. \& Blanke, D. J. (1986) Comparison of gait of young women and elderly women. Phyiscal Therapy. 66: 1382-1387.

- Judge, J. O., Davis, R. B. \& S., O. (1996) Step length reduction in advanced age: The role of ankle and hip kinetics. Journal of Gerontology: Medical Sciences. 51A: 303-312.

- Kahn, E. B., Ramsey, L. T., Brownson, R. C., Heath, G. W., Howze, E. H., Powell, K. E., Stone, E. J., Wajab, M. W. \& Corso, P. (2002) The effectiveness of intervention to increase physical activity: A systemic review. American Journal of Preventive Medicine. 22: 73-107.

- Kannel, W. B., Sorlie, P. (1979) Some health benefits of physical activity The Framingham Study. Arch of InternMedicine. 139(8): 857-861.
- Pate, R. R., Pratt, M., Blair, S. N., Haskell, W. L., Macera, C. A., Bouchard, C., Buchner, D., Ettinger, W., Heath, G. W., King, A. C., Kriska, A., Leon, A. S., Marcus, B. H., Morris, J., Paffenbarger, R. S., Patrick, K., Pollock, M. L., Rippe, J. M., Sallis, J., Wilmore, J. H. (1995) Physical activity and public health: A recommendation from the Centers for Disease Control and Prevention and the American College of Sports Medicine. . The journal of The American Medical Association. , 273, 402-407.

- Pitta, F., Troosters, T., Spruit, M. A., Probst, V. S., Decramer, M. \& Gosselink, R. (2005) Characteristics of physical activities in daily life in Chronic Obstructive Pulmonary Disease. American Journal Respiratory and Critical Care Medicine. 171: 972-977.

- Poh, H., Eastwood, P. R., Cecins, N. M., Ho, K. T., Jenkins, S. C. (2006) Six-minutes walk distance in healthy Singaporean adults cannot be predicted using reference equation derived from Caucasian population. Respirology. 11: $211-216$.

- Samson, M. M., Crowe, A., Vreede, P. L., Dessens, J. A., Duursma, S. A. \& Verhaar, H. J. (2001) Difference in gait parameters at a preferred walking speed in healthy subjects due to age, height and body weight. Aging. 13:16-21.

- Schutzer, K. A. \& Graves, B. S. (2004) Barriers and motivations to exercise in older adults. Preventive Medicine. 39: 1056-1061.

- Sherar, L. B., Esliger, D. W., Baxter-Jones, A. D. G. \& Tremblay, M. S. (2006) Age and Gender Differences in Youth Physical Activity : Does Maturity Matter? Medicine \& Sciences in Sports \& Exercise. 39: 830-835.

- Solway, S., Brooks, D., Lacasse, Y. \& Thomas, S. ( 2001 ) A qualitative systemic overview of the measurement properties of functional walk tests using in the cardiorespiratory domain. Chest. 119: 256-270.

- Wu, J., Luxton, N., Alison, J. \& Mackey, M. (2008) Relationship between field walking tests and incremental cycle ergometry in COPD. Respirology. Vol 13, No 6, 865862. Annals of Thoracic Medicine. 1: 16-19. 